\title{
Long-Term Outcomes in Patients with Very-Early Onset Autosomal Dominant Polycystic Kidney Disease
}

\author{
Kristen L. Nowak Melissa A. Cadnapaphornchai Michel B. Chonchol \\ Robert W. Schrier Berenice Gitomer \\ Division of Renal Diseases and Hypertension, University of Colorado Anschutz Medical Campus, Aurora, Colo., USA
}

\section{Key Words \\ Autosomal dominant polycystic kidney disease · Children . Epidemiology · Glomerular filtration rate · Hypertension . Longitudinal · Pediatrics · Total kidney volume}

\begin{abstract}
Background: Long-term clinical outcomes in children with very-early onset (VEO; diagnosis in utero or within the first 18 months of life) autosomal dominant polycystic kidney disease (ADPKD) are currently not well understood. We conducted a longitudinal retrospective cohort study to assess the association between VEO status and adverse clinical outcomes. Methods: Seventy patients with VEO-ADPKD matched (by year of birth, sex and race/ethnicity) to 70 patients with non-VEO-ADPKD who participated in research at the University of Colorado were studied. Kaplan-Meier survival analysis was performed. The predictor was VEO status, and outcomes were progression to end-stage renal disease (ESRD), development of hypertension, progression to estimated glomerular filtration rate (eGFR $\left.<90 \mathrm{ml} / \mathrm{min} / 1.73 \mathrm{~m}^{2}\right)$, glomerular hyperfiltration (eGFR $\geq 140 \mathrm{ml} / \mathrm{min} / 1.73 \mathrm{~m}^{2}$ ) and height-adjusted total kidney volume (htTKV) measured by $\mathrm{MRI} \geq 600 \mathrm{ml} / \mathrm{m}$. Results: Median follow-up was until 16.0 years of age. There were only 4 ESRD events during the follow-up period, all in the VEO group $(p<0.05)$. VEO patients were more likely to develop hypertension (hazard ratio, HR
\end{abstract}

$3.15,95 \% \mathrm{Cl} 1.86-5.34 ; \mathrm{p}<0.0001)$ and to progress to eGFR $<90 \mathrm{ml} / \mathrm{min} / 1.73 \mathrm{~m}^{2}$ (HR 1.97, 95\% Cl 1.01-3.84; $\mathrm{p}<0.05$ ) than non-VEO patients. There was no difference between groups in the development of glomerular hyperfiltration (HR $0.89,95 \% \mathrm{Cl} 0.56-1.42 ; \mathrm{p}=0.62)$. There were only 7 patients who progressed to htTKV $\geq 600 \mathrm{ml} / \mathrm{m}, 4$ in the VEO group and 3 in the non-VEO group $(p<0.01)$. Conclusions: Several clinical outcomes are worse in patients with VEO-ADPKD compared to non-VEO ADPKD. Children with VEO-ADPKD represent a particularly high-risk group of ADPKD patients.

ㄷ) 2016 S. Karger AG, Basel

Autosomal dominant polycystic kidney disease (ADPKD) is the most common inherited renal disease, estimated to affect 1:500 to 1:1,000 live births $[1,2]$. Although often considered to be a disease of adults, complications of ADPKD begin in childhood [3], with diagnosis possible in utero [4]. Children diagnosed either in utero or within the first 18 months of life are considered to have very-early onset (VEO) disease [5].

A previous cross-sectional analysis found that after adjustment for age, children with VEO-ADPKD were more likely to have hypertension, lower estimated glomerular filtration rate (eGFR) and larger age-adjusted kidney volume by ultrasound when compared to nonVEO ADPKD children diagnosed between 18 months

\section{KARGER}

E-Mail karger@karger.com www.karger.com/ajn (c) 2016 S. Karger AG, Basel

0250-8095/16/0443-0171\$39.50/0
Kristen L. Nowak, PhD, MPH

Division of Renal Diseases and Hypertension University of Colorado Anschutz Medical Campus 12700 E 19th Avenue, C281, Aurora, CO 80220 (USA)

E-Mail Kristen.Nowak@ucdenver.edu 
and 18 years of age [5]. Other studies have followed VEO patients over time, but have only considered the prevalence of outcomes of interest (e.g., end-stage renal disease (ESRD), hypertension) with a relatively small number of patients [6-9]. To date, a longitudinal time-to-event analysis comparing children with VEO-ADPKD to matched patients with non-VEO-ADPKD has not been performed. Thus, long-term clinical outcomes in children with VEO-ADPKD are currently not well understood.

Clinical outcomes of interest in early ADPKD include development of hypertension, increase in total kidney volume (TKV), development of glomerular hyperfiltration, decline in eGFR and progression to ESRD. Hypertension in patients with ADPKD is associated with both larger TKV and progression to ESRD [10]. Height-adjusted TKV (htTKV) measured by MRI predicts both the decline in eGFR measured by iothalamate clearance and progression to ESRD [11, 12]. Glomerular hyperfiltration has been shown to predict both increased kidney growth and a faster decline in renal function in children with ADPKD [13]. Both an early decline in eGFR and progression to ESRD are well appreciated, clinically relevant end points in ADPKD.

Accordingly, the aim of this study was to compare the development of clinically meaningful end points (hypertension, glomerular hyperfiltration, htTKV $\geq 600 \mathrm{ml} / \mathrm{m}$, eGFR $<90 \mathrm{ml} / \mathrm{min} / 1.73 \mathrm{~m}^{2}$ and ESRD) using time-toevent analysis in a cohort of VEO-ADPKD patients matched to non-VEO-ADPKD patients. We hypothesized that adverse clinical outcomes would occur at an earlier age in the VEO compared to non-VEO group.

\section{Subjects and Methods}

\section{Study Design}

Since 1985, the University of Colorado has maintained a registry of patients with ADPKD. Of the 2,126 patients currently in the registry who had data available on at least one of the outcomes of interest and age/year of diagnosis, we identified 70 ADPKD patients (3.3\%) as VEO (i.e., diagnosis in utero or within the first 18 months of life; online suppl. fig. 1; for all online suppl. material, see www.karger.com/doi/10.1159/000448695). In total, 534 (25.1\%) of these 2,126 patients were diagnosed with ADPKD prenatally or in childhood. The 70 patients identified as VEO participated in a longitudinal natural history study of ADPKD [3] $(\mathrm{n}=43)$ and/or completed or ongoing randomized placebo-controlled trials/genetic modifier study ( $\mathrm{n}=24$ total; angiotensin converting enzyme inhibitor (ACEI) study in children/young adults [14], $\mathrm{n}=19$; statin study in children/young adults [15], $\mathrm{n}=14$; mineralocorticoid antagonism study (NCT01853553), $\mathrm{n}=3$; genetic modifier study (U01DK079856), $\mathrm{n}=3$ ), or completed only survey data by ques- tionnaire $(\mathrm{n}=20)$. We also identified 70 ADPKD patients who were diagnosed after 18 months of age, matched to controls for age (year of birth \pm 3 years), sex and, when possible, race and ethnicity. These patients were also matched as closely as possible for study participation (longitudinal natural history study, $\mathrm{n}=28$; randomized placebo-controlled trials/genetic modifier study, $\mathrm{n}=32$ total (ACEI study, $\mathrm{n}=17$; statin study, $\mathrm{n}=21$; mineralocorticoid antagonism study, $\mathrm{n}=1$; genetic modifier study, $\mathrm{n}=2$; questionnaire only, $n=20)$ ). Follow-up visits for those who participated in intervention trials were only included in analysis if they were in the placebo group. All analysis was retrospective, and participants did not return specifically for this study.

The study was approved by the Colorado Multiple Institutional Review Board and conformed with the Declaration of Helsinki. The nature, benefits and risks of the study were explained to all participants and participant or parental written informed consent was obtained prior to participation. Participants consented to storage of data for future analyses at the time of consent to study participation. Children over 7 and under 18 years of age provided an assent.

\section{Study Variables}

Predictor

Patients with VEO ADPKD were identified as being diagnosed either in utero or within the first 18 months of life [5]. Matched patients with non-VEO ADPKD were identified as non-VEO based on diagnosis of ADPKD at $>18$ months of age. Diagnosis of ADPKD in children was based upon the presence of bilateral renal cysts by ultrasonography with a positive family history $[5,16]$. Importantly, any prenatal ultrasound was routine, mothers of VEO ADPKD patients were as equally likely to have received prenatal ultrasound and patients were matched as closely as possible for year of birth, thus accounting for changes in sensitivity of ultrasound over time.

\section{Outcomes}

Outcomes of interest, defined a priori, were development of hypertension, height-adjusted htTKV $\geq 600 \mathrm{ml} / \mathrm{m}$, glomerular hyperfiltration, eGFR $<90 \mathrm{ml} / \mathrm{min} / 1.73 \mathrm{~m}^{2}$ and progression to ESRD. htTKV $\geq 600 \mathrm{ml} / \mathrm{m}$ was selected because this threshold was shown to predict the risk of developing stage 3 chronic kidney disease (CKD) within 8 years in adults with ADPKD [11].

Progression to ESRD (all participants) and hypertension status ( $n=69$ VEO and $n=69$ non-VEO) were evaluated by a questionnaire asking whether the outcomes had occurred, and if so, in what year $[17,18]$. For participants in the natural history study or randomized controlled trials, multiple blood pressures and automatic blood pressures (Dinamap) were also taken in the seated position with an appropriately sized cuff based on arm circumference for evaluation of hypertension status (49 VEO and 49 non-VEO patients) $[5,14,15,19]$. In the natural history study, a mean of 16 measurements was calculated in adults [19], and on an average, 14 automatic measurements were taken and averaged in children [5]. In the randomized controlled trials, 12 blood pressures were averaged $[14,15]$. Hypertension was defined as mean systolic blood pressure $(\mathrm{SBP})>140 \mathrm{~mm} \mathrm{Hg}$ and/or diastolic blood pressure (DBP) $>90 \mathrm{~mm} \mathrm{Hg}$ in adults and as SBP $\geq 95$ th percentile for age, sex and height for children [20].

htTKV by abdominal MRI was determined using the stereology method, as described in detail previously (24 VEO and 33 non- 
VEO patients) [15, 21]. Only baseline data were included for participants in the statin study who were randomized to the active group, as pravastatin slowed the growth of htTKV [15]. In addition to $h t T K V \geq 600 \mathrm{ml} / \mathrm{m}$, we evaluated time to $\mathrm{htTKV} \geq 300 \mathrm{ml} / \mathrm{m}$ as a supplementary analysis.

eGFR was calculated in adults using the 4-variable Modified Diet Renal Disease prediction equation [22]. As older measurements of serum creatinine were not IDMS traceable, the CKD Epidemiology Collaboration equation was not used. eGFR was calculated in children using the old Schwartz formula [23] or the new Schwartz equation for time points after the switch to IDMS traceable measurements [24]. Data on eGFR were available in a total of 50 VEO and 50 non-VEO patients. Glomerular hyperfiltration was defined as eGFR $\geq 140 \mathrm{ml} / \mathrm{min} / 1.73 \mathrm{~m}^{2}$. A decline to eGFR $<90 \mathrm{ml} / \mathrm{min} / 1.73 \mathrm{~m}^{2}$ was selected as an end point in order to detect a more modest decline in renal function, given that GFR is largely preserved in children with ADPKD [3]. As a supplementary analysis, we also evaluated time to $30 \%$ decline in eGFR.

Other Measurements

Year of birth, age at diagnosis, race and ethnicity were determined from self-report. Cause of diagnosis was determined from medical history or self-report. Body mass index (BMI) was determined from height and weight measured during a physical examination (51 VEO and 50 non-VEO patients). DNA screening of the $P K D 1$ and $P K D 2$ genes were performed as described previously [25].

\section{Statistical Analyses}

The longitudinal association between VEO status and adverse outcomes of interest (development of hypertension, htTKV $\geq 600 \mathrm{ml} / \mathrm{m}$, glomerular hyperfiltration, eGFR $<90 \mathrm{ml} / \mathrm{min} / 1.73 \mathrm{~m}^{2}$ or progression to ESRD) was analyzed using Kaplan-Meier survival analysis and the log-rank test. The initial time point was defined as birth ( 0 years of age) for all participants. Participants were censored upon cessation of participation in any ADPKD studies. Differences in demographics and clinical characteristics between groups were assessed using t tests, chi-square tests or rank-based tests. Unadjusted Cox proportional hazards analysis was used to determine the hazard ratio (HR) for each outcome of interest. As potential covariates mediating outcomes did not differ between groups, and the progression in patients with VEO-ADPKD is of interest independent of mechanism, adjusted analyses were not performed. Two-tailed values of $\mathrm{p}<0.05$ were considered statistically significant. All statistical analyses were performed with SAS version 9.4 .

\section{Results}

\section{Clinical Characteristics}

Demographics and clinical characteristics at the final time point for VEO and non-VEO patients with ADPKD are shown in table 1 . Of note, some pairs of siblings were included in the study (7 VEO pairs, 2 non-VEO pairs, and $3 \mathrm{VEO} /$ non-VEO pairs). Patients were successfully matched for year of birth, sex and race/ethnicity. Overall, the median follow-up was until 16.0 (interquartile range 11.5-21.0) years of age, which did not differ significantly between groups. By definition, VEO patients were diagnosed at a younger age (i.e., $<18$ months) than non-VEO patients. VEO cases were more likely to be diagnosed in utero or due to abdominal mass/palpable kidneys, whereas non-VEO patients were more likely to be diagnosed due to other screening or to have not reported a known cause of diagnosis. Presence of the PKD1 genotype, BMI category, SBP, DBP, eGFR and htTKV were not significantly different between groups.

\section{Hypertension}

Forty-two (61\%) VEO and 21 (30\%) non-VEO patients developed hypertension in the follow-up period. VEO patients were more likely to develop hypertension during follow-up than non-VEO patients (fig. 1a; $\mathrm{p}<$ 0.0001 ). The median age at development of hypertension was 18 years earlier in the VEO group compared to the non-VEO group (table 2). A VEO patient who had not yet developed hypertension was $\sim 3$ times as likely to progress to hypertension at the next time point, as compared to a non-VEO patient (table 2).

\section{Kidney Growth}

There were only 7 patients who progressed to htTKV $\geq 600 \mathrm{ml} / \mathrm{m}$ during the follow-up period, $4(17 \%)$ in the VEO group and $3(9 \%)$ in the non-VEO group $(\mathrm{p}<0.001$; fig. 1b). The median age at time of htTKV $\geq 600 \mathrm{ml} / \mathrm{m}$ in the VEO group was 19 years. Due to the low number of events, the median age in the non-VEO group and a HR could not be calculated. Results were similar in supplementary analysis evaluating progression to htTKV $\geq 300 \mathrm{ml} / \mathrm{m}$ (online suppl. table 1 and fig. $2 \mathrm{a}$; HR 4.00, $95 \%$ CI 1.88-8.74).

\section{Glomerular Hyperfiltration}

There was no difference in the development of glomerular hyperfiltration (eGFR $\geq 140 \mathrm{ml} / \mathrm{min} / 1.73 \mathrm{~m}^{2}$ ) between groups (19 (38\%) in the VEO group and 24 (48\%) in the non-VEO group; fig. 1c; $\mathrm{p}=0.86$ ), with a non-significant HR (table 2).

\section{$e G F R<90 \mathrm{ml} / \mathrm{min} / 1.73 \mathrm{~m}^{2}$}

VEO patients were more likely to progress to eGFR $<90 \mathrm{ml} / \mathrm{min} / 1.73 \mathrm{~m}^{2}$ (fig. $1 \mathrm{~d} ; \mathrm{p}=0.034$ ). Twenty-five (50\%) VEO and 15 (30\%) non-VEO progressed to eGFR $<90 \mathrm{ml} / \mathrm{min} / 1.73 \mathrm{~m}^{2}$ during the follow-up period. The median age at progression to eGFR $<90 \mathrm{ml} / \mathrm{min} / 1.73 \mathrm{~m}^{2}$ 
Table 1. Clinical characteristics of VEO and non-VEO patients with ADPKD at the final time point

\begin{tabular}{|c|c|c|}
\hline Clinical characteristics & VEO & Non-VEO \\
\hline Gender $(\mathrm{M} / \mathrm{F})$ & $70(29 / 41)$ & $70(29 / 41)$ \\
\hline Year of birth, median (IQR) & $1992(1986-1996)$ & $1992(1986-1995)$ \\
\hline Age, years, median (IQR) & $15(9-21)$ & $17(13-21)$ \\
\hline Age at diagnosis, median (IQR) & $<18$ months & $10(6-14)$ years \\
\hline \multicolumn{3}{|l|}{ Race/ethnicity, \% (n) } \\
\hline Non-hispanic white & $64(45)$ & $73(51)$ \\
\hline Other & $7(5)$ & $10(7)$ \\
\hline Not reported & $29(20)$ & $17(12)$ \\
\hline \multicolumn{3}{|l|}{ Cause of diagnosis, \% (n) } \\
\hline In utero & $40(28)$ & $0(0)$ \\
\hline Screening by imaging (other than in utero) & $19(13)$ & $34(24)$ \\
\hline Abdominal mass/palpable kidneys & $13(9)$ & $4(3)$ \\
\hline Hypertension & $0(0)$ & $1(1)$ \\
\hline Other symptoms & $7(5)$ & $16(11)$ \\
\hline Not reported & $21(15)$ & $44(31)$ \\
\hline \multicolumn{3}{|l|}{ PKD1 genotype, \% (n) } \\
\hline Yes & $47(33)$ & $31(22)$ \\
\hline No mutation detected & $1(1)$ & $1(1)$ \\
\hline Unknown & $51(36)$ & $67(47)$ \\
\hline \multicolumn{3}{|l|}{ BMI category, \% (n) } \\
\hline Normal or underweight & $46(33)$ & $42(30)$ \\
\hline Overweight & $14(10)$ & $13(9)$ \\
\hline Obese & $11(8)$ & $15(11)$ \\
\hline Not reported & $27(19)$ & $28(20)$ \\
\hline $\mathrm{SBP}, \mathrm{mm} \mathrm{Hg}$, mean $\pm \mathrm{SD}$ & $116 \pm 23$ & $120 \pm 14$ \\
\hline $\mathrm{DBP}, \mathrm{mm} \mathrm{Hg}$, mean $\pm \mathrm{SD}$ & $71 \pm 13$ & $71 \pm 10$ \\
\hline eGFR, $\mathrm{ml} / \mathrm{min} / 1.73 \mathrm{~m}^{2}$, median (IQR) & $109(81-128)$ & $108(93-128)$ \\
\hline $\mathrm{htTKV}, \mathrm{ml} / \mathrm{m}$, median (IQR) & $370(214-544)$ & $281(224-471)$ \\
\hline
\end{tabular}

Data from the final time point for each variable are shown and may represent a slightly different time point for each variable.

IQR = Interquartile range. Data were not reported for SBP and DBP (21 VEO, 21 non-VEO patients), eGFR (20 VEO, 20 non-VEO patients), htTKV (46 VEO, 37 non-VEO patients).

was 3 years earlier in the VEO group compared to the non-VEO group (table 2). A VEO patient who had not yet progressed to eGFR $<90 \mathrm{ml} / \mathrm{min} / 1.73 \mathrm{~m}^{2}$ was $\sim 2$ times as likely to progress to eGFR $<90 \mathrm{ml} / \mathrm{min} / 1.73 \mathrm{~m}^{2}$ at the next time point as compared to a non-VEO patient (table 2). However, in supplementary post-hoc analyses, there was no difference in time to a $30 \%$ decline in eGFR (online suppl. table 1 and fig. 2b; HR 1.23, 95\% CI 0.503.10).

\section{End-Stage Renal Disease}

There were only 4 ESRD events during the follow-up period, all of which occurred in the VEO group $(6 \% ; p=$ 0.031; Kaplan-Meier curve not shown). Due to the low number of events, the median age at ESRD and a HR could not be calculated.

\section{Discussion}

In the largest study of VEO-ADPKD patients to date, and the first longitudinal analysis of clinical end points, we found a greater hazard of adverse outcomes in a cohort of patients with VEO-ADPKD compared to nonVEO-ADPKD followed until a median age of 16 years. VEO-ADPKD was associated with development of hypertension, increase in htTKV to $\geq 600 \mathrm{ml} / \mathrm{m}$, eGFR $<90 \mathrm{ml} / \mathrm{min} / 1.73 \mathrm{~m}^{2}$ and ESRD, with no difference in glomerular hyperfiltration. Importantly, the patients with VEO-ADPKD were matched for year of birth, sex and, when possible, race/ethnicity; thus it is unlikely that differences between groups were due to a cohort effect.

A previous cross-sectional analysis from our group also compared outcomes in VEO and non-VEO-ADPKD 
Table 2. Median time to events for included VEO and non-VEO patients with ADPKD

\begin{tabular}{lllllr}
\hline Event & $\begin{array}{l}\text { VEO, } \\
\text { n }(\%)\end{array}$ & $\begin{array}{l}\text { Age VEO, } \\
\text { median }\end{array}$ & $\begin{array}{l}\text { Non-VEO, } \\
\text { n }(\%)\end{array}$ & $\begin{array}{l}\text { Age non-VEO, } \\
\text { median }\end{array}$ & $\begin{array}{l}\text { HR } \\
(95 \% \mathrm{CI})\end{array}$ \\
\hline Hypertension & $42(61)$ & 20 & $21(30)$ & 38 & $3.15(1.86-5.34)$ \\
eGFR $\geq 140 \mathrm{ml} / \mathrm{min} / 1.73 \mathrm{~m}^{2}$ & $19(38)$ & $\mathrm{N} / \mathrm{A}$ & $24(48)$ & $\mathrm{N} / \mathrm{A}$ & $<0.0001$ \\
eGFR $<90 \mathrm{ml} / \mathrm{min} / 1.73 \mathrm{~m}^{2}$ & $25(50)$ & 22 & $15(30)$ & 25 & $\begin{array}{r}1.06(0.58-1.93) \\
2.30(1.08-3.95)\end{array}$ \\
\hline
\end{tabular}

$\mathrm{N} / \mathrm{A}=$ The median estimate could not be calculated because the failure probability never exceeded 0.5 . HRs and $\mathrm{p}$ values are for unadjusted Cox proportional hazards analysis comparing VEO to non-VEO.

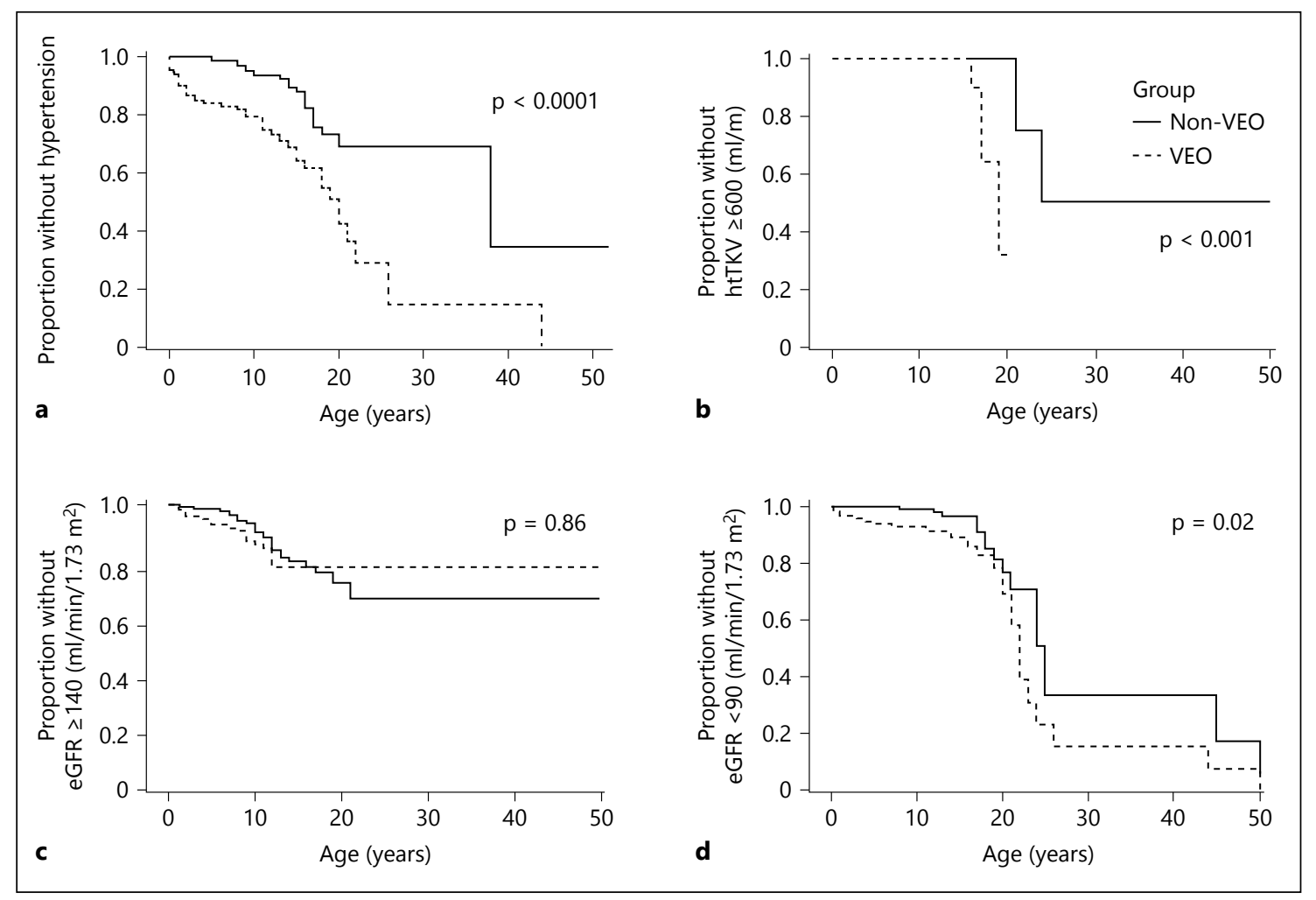

Fig. 1. Kaplan-Meier curve of hypertension (a), htTKV $\geq 600 \mathrm{ml} / \mathrm{m}$ (b), glomerular hyperfiltration (eGFR $\geq 140 \mathrm{ml} / \mathrm{min} / 1.73 \mathrm{~m}^{2}$; c) and eGFR $<90 \mathrm{ml} / \mathrm{min} / 1.73 \mathrm{~m}^{2}$ (d) according to group (VEO or non-VEO ADPKD). VEO patients were more likely to develop hy-

patients with adjustment for age [5]. At this single time point, VEO patients had a lower eGFR and higher ageadjusted kidney volume measured by ultrasound. Two VEO and no non-VEO patients reached ESRD, which was a similar low rate to the present study. Additionally, VEO patients were more likely to have hypertension during the follow-up period as evaluated by questionnaire. The current study expands upon these previous findings by following a longitudinal cohort of a larger number of pertension, to progress to htTKV $>600 \mathrm{ml} / \mathrm{m}$ and to decline to eGFR $<90 \mathrm{ml} / \mathrm{min} / 1.73 \mathrm{~m}^{2}$ than non-VEO patients, but did not differ in progression to glomerular hyperfiltration.

VEO-ADPKD patients with matched non-VEO-ADPKD controls for the development of clinically meaningful outcomes.

The greater development of adverse outcomes in the VEO group supports the need for early identification and intervention of ADPKD in children, particularly in those with VEO. Early intervention may have the greatest effect on the course of the disease by minimizing long-term complications [26, 27]. Given that there is great hetero- 
geneity in ADPKD progression, even within a given family [10], early intervention may be of particular significance to patients at the highest risk of progression, which notably includes VEO patients.

The median age of onset of hypertension was 18 years earlier in VEO compared to non-VEO patients. High blood pressure in affected children (above the 75th percentile for age, sex and height) is associated with faster renal growth [3]. Hypertension is also associated with larger TKV in adults and children [10], as well as a decline in renal function $[28,29]$. Notably, in the recently completed Halt Progression of PKD blood pressure trial, rigorous blood pressure control slowed the increase in TKV compared to standard blood pressure control [30].

VEO-ADPKD was also associated with progression to $\mathrm{htTKV} \geq 600 \mathrm{ml} / \mathrm{min}$, albeit with a relatively low number of events occurring overall. This value was selected as an end point because baseline htTKV $\geq 600 \mathrm{ml} / \mathrm{min}$ predicted progression to stage $3 \mathrm{CKD}$ within 8 years in the Consortium for Radiologic Imaging Studies of PKD [11]. Additionally, increased htTKV at a younger age is clinically significant, as severe renal enlargement at a young age is associated with faster renal growth [3]. Results were similar in sensitivity analyses considering an earlier end point of htTKV $\geq 300 \mathrm{ml} / \mathrm{min}$. Importantly, as kidney growth is associated with declining kidney function over time [14, $31,32]$, the greater progression to htTKV $\geq 600$ or $\geq 300 \mathrm{ml} / \mathrm{min}$ would suggest greater risk of progression to ESRD in children with VEO-ADPKD.

A decline in eGFR $<90 \mathrm{ml} / \mathrm{min} / 1.73 \mathrm{~m}^{2}$ was selected as an end point in order to detect a more modest decline in renal function, given that GFR is largely preserved in children with ADPKD [3]. Since GFR is typically maintained in the normal range in ADPKD until the 4 th or 5 th decade of life [33], a higher risk of progression to eGFR $<90 \mathrm{ml} /$ $\mathrm{min} / 1.73 \mathrm{~m}^{2}$ is clinically significant. A higher serum creatinine at baseline has been shown to predict a faster decline in eGFR in a cohort of 200 ADPKD patients [34]. However, unlike decline to $<90 \mathrm{ml} / \mathrm{min} / 1.73 \mathrm{~m}^{2}$, there was no difference between groups in time to $30 \%$ decline in eGFR, perhaps because it is a less subtle change in renal function. The number of patients that progressed to ESRD (4, all VEO) was low, consistent with earlier data [5]. Of note, the development of ESRD in ADPKD is highly variable, ranging from childhood to a normal life expectancy without knowledge of disease [33].

There was no difference in glomerular hyperfiltration $\left(\mathrm{eGFR} \geq 140 \mathrm{ml} / \mathrm{min} / 1.73 \mathrm{~m}^{2}\right.$ ) between the VEO and nonVEO-ADPKD group. In ADPKD, compensatory hyperfiltration occurs to initially maintain normal or near nor- mal serum creatinine levels, despite progressive destruction of the parenchyma [35]. Glomerular hyperfiltration leads to glomerular hypertension and progressive damage of the remaining unaffected nephrons [36]. In children with ADPKD, glomerular hyperfiltration is associated with an increased rate of kidney growth and a faster decline in eGFR [13]. However, the present results indicate that glomerular hyperfiltration is not an important mechanism differentiating progression in VEO and nonVEO patients with APDKD.

Of note, we feel it is unlikely that the included VEO patients had very severe ADPKD, resulting from coinheritance of a hypomorphic PKD1 allele in trans with an inactivating PKD1 allele $[37,38]$. Such cases present phenotypically similar to autosomal recessive PKD, and no participants in this cohort had such severe symptoms. The inheritance of 2 incompletely penetrant $\mathrm{PKD} 1$ alleles is the likely explanation for early case reports that reported very high mortality in the first year of life for patients with VEO-ADPKD $[39,40]$. Data were available regarding PKD genotype in a sub-sample of participants in the present study and did not differ between groups. Whether the prevalence of the PKD1 genotype is greater in VEO-ADPKD patients is currently unknown.

There are several important limitations to the present study. As all analysis was retrospective, this introduces various biases and limitations, including selection bias, information bias, loss to follow-up and missing data. This cohort may not accurately reflect the natural course of disease progression as it is biased by the participation in research studies. Furthermore, as this is an observational study, it can only show association rather than causation. Due to the nature of follow-up, the exact time of each event may have differed slightly from what was reported or measured. Additionally, not all outcomes or covariates were available in all participants, and some outcomes were self-reported. Similarly, further variables of interest were not available for inclusion in the study, including albuminuria/proteinuria, urinary tract infections and additional markers of hyperfiltration. The influence of VEO status on progression to ESRD will require long-term follow-up for more definitive insight. VEO participants may have been followed more carefully or may have been more likely to have outcomes of interest detected earlier due to earlier diagnosis. However, as non-VEO patients were also diagnosed nearly exclusively in childhood, this concern is minimized. Of note, the non-VEO patients in our population are possibly more affected than the general ADPKD population, many of whom are affected but undiagnosed. Outside physicians are more likely to refer 
patients with more severe disease for participation in studies.

Our definition of VEO to include individuals diagnosed due to screening or even in utero may have resulted in inclusion of patients who were not truly VEO due to symptoms. However, this definition would have reduced our ability to detect a difference between groups and the disparity between groups may be even greater than assessed. Additionally, mothers of VEO patients were not more likely to receive prenatal ultrasound screening than mothers of non-VEO patients. Last, detailed information on mutation type was unavailable on the vast majority of participants and is an important future direction in this field. Notable strengths of this study include inclusion of the largest number of VEO-ADPKD patients to date. Additionally, matching for year of birth, sex and, when possible, race/ethnicity minimized potential confounding. Due to the matching by birth year, it is unlikely that difference between groups were due to a cohort effect (e.g., improved ultrasound technology in more recent years leading to increased detection of ADPKD in utero). Importantly, this is the first study to examine lon- gitudinal outcomes in VEO-ADPKD patients, with a median follow-up period to 16 years of age.

In conclusion, the results are consistent with the hypothesis that several adverse outcomes are worse in patients with VEO-ADPKD compared to non-VEO ADPKD, thus children with VEO-ADPKD represent a particularly high-risk group of ADPKD patients. Longterm follow-up is needed to provide even greater insight to the clinical course of patients with VEO-ADPKD. It is likely that even more VEO cases will be identified in the future due to advances in ultrasound imaging.

\section{Acknowledgments}

This work was supported by National Institutes of Health awards (DK103678, DK097081, DK058793, DK034039 and UL1 TR001082).

\section{Disclosure Statement}

B.G. and M.B.C. have received research funding from Otsuka, which did not support the current study.

\section{References}

1 Torres VE, Harris PC, Pirson Y: Autosomal dominant polycystic kidney disease. Lancet 2007;369:1287-1301.

2 Ong AC, Devuyst O, Knebelmann B, Walz G: Autosomal dominant polycystic kidney disease: the changing face of clinical management. Lancet 2015;385:1993-2002.

3 Fick-Brosnahan GM, Tran ZV, Johnson AM, Strain JD, Gabow PA: Progression of autosomal-dominant polycystic kidney disease in children. Kidney Int 2001;59:1654-1662.

4 Pretorius DH, Lee ME, Manco-Johnson ML, Weingast GR, Sedman AB, Gabow PA: Diagnosis of autosomal dominant polycystic kidney disease in utero and in the young infant. J Ultrasound Med 1987;6:249-255.

5 Shamshirsaz AA, Reza Bekheirnia M, Kamgar M, Johnson AM, McFann K, Cadnapaphornchai M, Nobakhthaghighi N, Schrier RW: Autosomal-dominant polycystic kidney disease in infancy and childhood: progression and outcome. Kidney Int 2005;68:2218-2224.

6 Fick GM, Johnson AM, Strain JD, Kimberling WJ, Kumar S, Manco-Johnson ML, Duley IT, Gabow PA: Characteristics of very early onset autosomal dominant polycystic kidney disease. J Am Soc Nephrol 1993;3:1863-1870.

7 Sedman A, Bell P, Manco-Johnson M, Schrier R, Warady BA, Heard EO, Butler-Simon N, Gabow P: Autosomal dominant polycystic kidney disease in childhood: a longitudinal study. Kidney Int 1987;31:1000-1005.
8 Boyer O, Gagnadoux MF, Guest G, Biebuyck N, Charbit M, Salomon R, Niaudet P: Prognosis of autosomal dominant polycystic kidney disease diagnosed in utero or at birth. Pediatr Nephrol 2007;22:380-388.

9 Tee JB, Acott PD, McLellan DH, Crocker JF: Phenotypic heterogeneity in pediatric autosomal dominant polycystic kidney disease at first presentation: a single-center, 20-year review. Am J Kidney Dis 2004;43:296-303.

10 Schrier RW, Brosnahan G, Cadnapaphornchai MA, Chonchol M, Friend K, Gitomer B, Rossetti S: Predictors of autosomal dominant polycystic kidney disease progression. J Am Soc Nephrol 2014;25:2399-2418.

11 Chapman AB, Bost JE, Torres VE, GuayWoodford L, Bae KT, Landsittel D, Li J, King BF, Martin D, Wetzel LH, Lockhart ME, Harris PC, Moxey-Mims M, Flessner M, Bennett WM, Grantham JJ: Kidney volume and functional outcomes in autosomal dominant polycystic kidney disease. Clin J Am Soc Nephrol 2012;7:479-486.

12 Grantham JJ, Torres VE, Chapman AB, Guay-Woodford LM, Bae KT, King BF Jr, Wetzel LH, Baumgarten DA, Kenney PJ, Harris PC, Klahr S, Bennett WM, Hirschman GN, Meyers CM, Zhang X, Zhu F, Miller JP: Volume progression in polycystic kidney disease. N Engl J Med 2006;354:2122-2130.

13 Helal I, Reed B, McFann K, Yan XD, FickBrosnahan GM, Cadnapaphornchai $M$,
Schrier RW: Glomerular hyperfiltration and renal progression in children with autosomal dominant polycystic kidney disease. Clin J Am Soc Nephrol 2011;6:2439-2443.

14 Cadnapaphornchai MA, McFann K, Strain JD, Masoumi A, Schrier RW: Prospective change in renal volume and function in children with ADPKD. Clin J Am Soc Nephrol 2009;4:820-829.

15 Cadnapaphornchai MA, George DM, McFann K, Wang W, Gitomer B, Strain JD, Schrier RW: Effect of pravastatin on total kidney volume, left ventricular mass index, and microalbuminuria in pediatric autosomal dominant polycystic kidney disease. Clin J Am Soc Nephrol 2014;9:889-896.

16 Reed B, Nobakht E, Dadgar S, Bekheirnia MR, Masoumi A, Belibi F, Yan XD, Cadnapaphornchai M, Schrier RW: Renal ultrasonographic evaluation in children at risk of autosomal dominant polycystic kidney disease. Am J Kidney Dis 2010;56:50-56.

17 Fain PR, McFann KK, Taylor MR, Tison M, Johnson AM, Reed B, Schrier RW: Modifier genes play a significant role in the phenotypic expression of PKD1. Kidney Int 2005;67: 1256-1267.

18 Helal I, McFann K, Reed B, Yan XD, Schrier RW, Fick-Brosnahan GM: Serum uric acid, kidney volume and progression in autosomal-dominant polycystic kidney disease. Nephrol Dial Transplant 2013;28:380-385. 
19 Schrier RW, Johnson AM, McFann K, Chapman $\mathrm{AB}$ : The role of parental hypertension in the frequency and age of diagnosis of hypertension in offspring with autosomal-dominant polycystic kidney disease. Kidney Int 2003;64:1792-1799.

20 National High Blood Pressure Education Program Working Group on High Blood Pressure in Children and Adolescents: The fourth report on the diagnosis, evaluation, and treatment of high blood pressure in children and adolescents. Pediatrics 2004;114:555-576.

21 Cadnapaphornchai MA, Masoumi A, Strain JD, McFann K, Schrier RW: Magnetic resonance imaging of kidney and cyst volume in children with ADPKD. Clin J Am Soc Nephrol 2011;6:369-376.

22 Levey AS, Bosch JP, Lewis JB, Greene T, Rogers N, Roth D: A more accurate method to estimate glomerular filtration rate from serum creatinine: a new prediction equation. Modification of diet in renal disease study group. Ann Intern Med 1999;130:461-470.

23 Schwartz GJ, Haycock GB, Edelmann CM Jr, Spitzer A: A simple estimate of glomerular filtration rate in children derived from body length and plasma creatinine. Pediatrics 1976; 58:259-263.

24 Schwartz GJ, Muñoz A, Schneider MF, Mak RH, Kaskel F, Warady BA, Furth SL: New equations to estimate GFR in children with CKD. J Am Soc Nephrol 2009;20:629-637.

25 Reed B, McFann K, Kimberling WJ, Pei Y, Gabow PA, Christopher K, Petersen E, Kelleher C, Fain PR, Johnson A, Schrier RW: Presence of de novo mutations in autosomal dominant polycystic kidney disease patients without family history. Am J Kidney Dis 2008;52: 1042-1050.

26 Grantham JJ: Rationale for early treatment of polycystic kidney disease. Pediatr Nephrol 2015;30:1053-1062.
27 Cadnapaphornchai MA: Autosomal dominant polycystic kidney disease in children. Curr Opin Pediatr 2015;27:193-200.

28 Johnson AM, Gabow PA: Identification of patients with autosomal dominant polycystic kidney disease at highest risk for end-stage renal disease. J Am Soc Nephrol 1997;8:15601567.

29 Ozkok A, Akpinar TS, Tufan F, Kanitez NA, Uysal M, Guzel M, Caliskan Y, Alisir S, Yazici $\mathrm{H}$, Ecder T: Clinical characteristics and predictors of progression of chronic kidney disease in autosomal dominant polycystic kidney disease: a single center experience. Clin Exp Nephrol 2013;17:345-351.

30 Schrier RW, Abebe KZ, Perrone RD, Torres VE, Braun WE, Steinman TI, Winklhofer FT, Brosnahan G, Czarnecki PG, Hogan MC, Miskulin DC, Rahbari-Oskoui FF, Grantham JJ, Harris PC, Flessner MF, Bae KT, Moore CG, Chapman AB: Blood pressure in early autosomal dominant polycystic kidney disease. N Engl J Med 2014;371: 2255-2266

31 Chapman AB, Guay-Woodford LM, Grantham JJ, Torres VE, Bae KT, Baumgarten DA, Kenney PJ, King BF Jr, Glockner JF, Wetzel LH, Brummer ME, O’Neill WC, Robbin ML, Bennett WM, Klahr S, Hirschman GH, Kimmel PL, Thompson PA, Miller JP: Renal structure in early autosomal-dominant polycystic kidney disease (ADPKD): the consortium for radiologic imaging studies of polycystic kidney disease (CRISP) cohort. Kidney Int 2003;64:1035-1045.

32 Fick-Brosnahan GM, Belz MM, McFann KK, Johnson AM, Schrier RW: Relationship between renal volume growth and renal function in autosomal dominant polycystic kidney disease: a longitudinal study. Am J Kidney Dis 2002;39:1127-1134.
33 Grantham JJ, Chapman AB, Torres VE: Volume progression in autosomal dominant polycystic kidney disease: the major factor determining clinical outcomes. Clin J Am Soc Nephrol 2006;1:148-157.

34 Klahr S, Breyer JA, Beck GJ, Dennis VW, Hartman JA, Roth D, Steinman TI, Wang SR, Yamamoto ME: Dietary protein restriction, blood pressure control, and the progression of polycystic kidney disease. Modification of diet in renal disease study group. J Am Soc Nephrol 1995;5:2037-2047.

35 Grantham JJ: Clinical practice. Autosomal dominant polycystic kidney disease. N Engl J Med 2008;359:1477-1485.

36 Grantham JJ, Mulamalla S, Swenson-Fields KI: Why kidneys fail in autosomal dominant polycystic kidney disease. Nat Rev Nephrol 2011;7:556-566.

37 Rossetti S, Kubly VJ, Consugar MB, Hopp K, Roy S, Horsley SW, Chauveau D, Rees L, Barratt TM, van't Hoff WG, Niaudet $P$, Torres VE, Harris PC: Incompletely penetrant PKD1 alleles suggest a role for gene dosage in cyst initiation in polycystic kidney disease. Kidney Int 2009;75:848-855.

38 Vujic M, Heyer CM, Ars E, Hopp K, Markoff A, Orndal C, Rudenhed B, Nasr SH, Torres VE, Torra R, Bogdanova N, Harris PC: Incompletely penetrant PKD1 alleles mimic the renal manifestations of ARPKD. J Am Soc Nephrol 2010;21:1097-1102.

39 MacDermot KD, Saggar-Malik AK, Economides DL, Jeffery S: Prenatal diagnosis of autosomal dominant polycystic kidney disease (PKD1) presenting in utero and prognosis for very early onset disease. J Med Genet 1998;35: 13-16.

40 Michaud J, Russo P, Grignon A, Dallaire L, Bichet $\mathrm{D}$, Rosenblatt $\mathrm{D}$, Lamothe E, Lambert M: Autosomal dominant polycystic kidney disease in the fetus. Am J Med Genet 1994;51:240-246. 